Article

\title{
Logistics Education and Behavioral Training Decisions, Time Distortion, and the Prae Ante View
}

\author{
Thomas Neukirchen ${ }^{1, *(\mathbb{D})}$ and Matthias Klumpp ${ }^{1,2}$ (D) \\ 1 Institute for Logistics and Service Management, FOM University of Applied Sciences, Leimkugelstr. 6, \\ 45141 Essen, Germany; matthias.klumpp@fom.de \\ 2 Department of Industrial Engineering and Business Information Systems (IEBIS), University of Twente, \\ Enschede, The Netherlands \\ * Correspondence: thomas.neukirchen@fom.de; Tel.: +49-201-81004-992
}

Received: 12 September 2018; Accepted: 15 October 2018; Published: 18 October 2018

check for updates

\begin{abstract}
In training and education for logistics, time inconsistency affects individual decisions regarding education and career choices. This is especially relevant in view of growing boundarylessness of careers that impacts the logistics sector with its high ratio of lateral entrants. We enrich the analysis of training and education decision-making processes with a third view beyond the common ex ante and ex post perspectives that has not been employed yet in this context. Our insights, modeled as a new prae ante view, can help prevent myopia in educational choice on an individual level and the resulting economic inefficiencies. This translates into more fitting provisions by individuals earlier, and into improved targeting of prospective employees in logistics. The purpose of this study is to provide an agent-based description grounded in behavioral economics, supported by an explorative empirical survey using extensive semi-structured expert-interviews with six participants concerning four to six career transitions each, conducted with employees in logistics professions. Main conclusions include that participants who were asked openly about influential factors for education and career decisions were oblivious of some factors described as highly predictive of educational and career success in literature, not acknowledging social and cultural capital, habitus, and chance, but also consistently ascribing success to a "milestone-mindset" to be described here as well.
\end{abstract}

Keywords: logistics education; logistics training; time inconsistency; vocational decision-making; information acquisition; prae ante

\section{Introduction}

Career paths have been reported as becoming increasingly non-linear ("boundaryless") in recent years [1,2], which includes voluntary job changes [3]. Since logistics intersects with many other sectors and has a high prevalence of lateral entries, employing an inclusive perspective regarding factors influencing early career decisions in academic work is likely to benefit practitioners, e.g., in the provision of more efficient onboarding processes. We aim to contribute to logistics research regarding human resource management (HRM) questions with an agent-based description grounded in behavioral economics. This is supported by an explorative empirical survey using semi-structured expert interviews conducted with employees from logistics professions. In logistics and supply chain management (SCM), this area appears under-researched, as has been noted by Huo et al. [4] (p. 717), "empirical research on the interface between HRM and SCM remains scarce and important issues remain unexplored". This interface is the location of our research into individual decisions regarding education and career choices in logistics and into logistics by lateral entry, the latter being a likely cause for friction costs related with onboarding measures, for instance. As much as the importance of 
specific logistics education and training is beyond dispute [5-7], the issue of time-inconsistent choices in that regard has rarely been addressed, which appears especially striking given the high occurrence of track changes leading employees into logistics as lateral entrants [8-10]. Time inconsistency is a well-established topic in behavioral economics [11-14], while basic or continuing education and training are discussed in research in many contexts including our instance regarding the context of time-inconsistent educational choice in logistics.

In our approach, all levels of education and training in logistics (vocational, academic, and continuing) are involved $[15,16]$. In this contribution, three perspectives are discerned, two of which are commonplace in economic theory. Usually, economic theory describes a decision perspective from an ex ante and ex post view. We deem this an unjustified limitation and propose an extended framework including a new "prae ante" view, for which this paper provides qualitative insights into the influential factors for this additional analytical perspective. Educational and career choices can be seen as investments in one's own human capital and are often analyzed both strategically (ex ante) and evaluated (ex post). In the economic analysis of intertemporal investment decisions, ex ante concerns the decision given the preferences, expectations, and information on the future $[17,18]$; meanwhile, ex post concerns an evaluation of decision outcomes in hindsight, for instance, by attaching monetary values to such outcomes [19]. We aim to enrich this paradigm with the introduction of a third view, which is particularly relevant to environments characterized by a high prevalence of lateral entries. Thus, our examples and data inputs are taken from the particular context of logistics education and training. On an individual level, the reasons for such career choices are complex, which may suggest the use of biographical interviews as a method [20]. Though potentially the most exhaustive, the evaluation of such sources requires categorization by the researcher at some point, which is where emphasis and weighting happens, and blind spots are bound to occur, as with every single method-approach vis-à-vis mixed methods, as is stressed e.g., by [21]. We chose guided interviews with employees from logistics management as an exploratory method that aims at gathering information on factors informing the decision that happens at the point in time called "ex ante," and which stem from a potentially long timespan beforehand. This is justified as we are interested in identifying factors that can be operationalized such that it is possible to conduct ensuing confirmatory research with larger samples, as well as to develop benchmarks for increased efficiency in individual decisions regarding education and training.

This contribution marks a first step in our research, which overall follows the idea of triangulation. In the language of the data triangulation methodology, as explained, for instance, by Mangan et al. [22], Easterby-Smith et al. [23], and Ticehurst and Veal [24], the current paper constitutes phase 1, which is inductive, to be succeeded by phase 2 (deductive), which is conceptualized to deal with results of a large sample survey built on the findings of the exploratory research conducted in this work. To refine phase 2, a third phase can then be employed to validate the findings from the preceding one (compare Reference [22], p. 570).

Recently, the importance of human resources, related education, and training with regard to the ever-growing complexity of supply chains and supply chain-environments has been stressed [4]. It has been noted that HR aspects have not received due attention especially with respect to supply chain integration [25-27]. Sweeney [25] explicitly attributes a lack of implementation of theoretically well-examined SCM-procedures to the neglect of HR-aspects, especially the "people dimension". As has been noted in Reference [4] (p. 717), "empirical research on the interface between HRM and SCM remains scarce and important issues remain unexplored." This also holds true for supply chain integration (SCI), where partnerships and collaboration are crucial factors [25]. Further potential for research has been identified regarding the scope of work dealing with HR issues: as References $[4,26]$ note, the main focus group of research lately has been managers, rather than employees.

Looking at the skill requirements for employees, a general mismatch of practitioners' and educators' beliefs about necessary skills has been found, as practitioners favor "tacit skills," for instance, communication, problem-solving and decision-making over management- or finance-related 
knowledge, which are favored by educators, while the importance of analytical and interpersonal skills has been stressed by both viewpoints [22,28]. Wu et al. [29] identify a broad array of skills deemed important by practitioners and educators: practitioners stress skills, such as having an international perspective, the ability to communicate and negotiate in more than one language, decision-making, risk management, understanding of cultural differences, market sensitivity, integrity, and the ability to analyze industry trends. On the other hand, educators' preferences tend to be skewed towards managerial abilities: upon being asked to rank skills from an exploratory list, foreign languages, communication, and the integration of systems, processes, and information in general, as well as logical thinking, problem solving, information research, and skills related to planning were ranked among the most important [29].

Though the perspectives of educators and practitioners do not match entirely, they intersect at the proposition that managerial skills are given priority over technical, specialized skills in logistics positions. In Murphy's and Poist's [30] work, we already find survey results listing SCM, customer service, motivational abilities, transportation and logistics, inventory management, integrity, business ethics, transport and traffic management, and decision-making as most relevant skills. Other, more recent studies still highlight managerial and communication skills as well [28,31,32] and assess the importance of technical skills as secondary.

All of the studies mentioned in this section agree on the inclusion of decision-making as a high-priority skill [33]. A notable, distinctive attribute of the logistics sector is its high ratio of employees who joined as lateral entrants $[9,34]$. An attribute, which might find an explanation in the constituents of the prae ante-view. The large number of lateral entries into logistics as well as the issue of education and training being underrepresented in research provide us with opportunities. Here, we will focus on the question of factors influencing education and training decisions from an early point in an individual's career, which in most cases means, from an early age, factors which may inform an individual's decision to take part in education and training programs, which in our example, are logistics-related. "Factors" are defined primarily as the constituents of the prae ante view. It will become clear that research opportunities exist regarding the issue of education and training decisions at the individual level, informing factors and influences from an early age, examined using qualitative methods.

The remainder of this paper is structured as follows: Section 2 provides descriptions of the three perspectives that can be used to examine individual decisions, such as the one given here, to partake in education and training ex post (Section 2.1) and ex ante (Section 2.2). In Section 2.3, we introduce our new perspective on the decision, the "prae ante"-view: we explore and examine decision-informing factors on an individual level, probably arising from an early age up to a point in time just before the actual decision happens. Section 3 elaborates on materials and methods (Section 3.1) and presents our survey results (Section 3.2). Section 4 contains a sketch of its further theoretical foundation. Lastly, Section 5 gives the results and discussion.

\section{Conceptual Background-Perspectives on Educational Choice}

\subsection{Ex Post}

The decision to partake in formal education and training or non-compulsory education programs can be examined individually as well as from the corporate perspective from an investment point of view [35]. "Schooling, experience, and earnings," with its well-known regression equation (the Mincer earnings function, which explains earnings via schooling and experience), has found countless applications since. The notions of risk and uncertainty remain abstract in such contexts, besides taking the form of some descriptive parameter as in the expected utility model [36]; for a discussion regarding paramorphic versus homeomorphic models, see Reference [18]. With a purely descriptive approach, two views are commonly distinguished, ex ante and ex post. Many econometric models of the latter type are variations of the Mincer model. Then, for an ex ante-perspective, the individual decision 
maker can be scrutinized more closely, which leads to all matters related to expressed preference in general and, in particular, time preference.

Here, we are interested in what we call the prae ante view: the period of time leading up to the actual decision. We ask what form time preference may take in this interval, how the ex ante choice depends on it, what qualitative factors are most influential in an individual's decision at that point, and how previous education and contextual experiences affect it, and conduct an empirical survey to establish reliable data for the area of logistics education and training. We reckon that most of the factors influencing the decision from the prae ante view are of a qualitative nature but are highly influential in the shaping of education and thus merit proper operationalization for thorough, quantitative research.

\subsection{Ex Ante}

The ex ante perspective is characterized via a strategic, game theoretic situation an individual faces (knowingly or not) when confronted with intertemporal choice. A succinct description of hyperbolic discounting (HD), the most popular non-standard time discounting model, has been given by Prelec:

The well-known distinguishing feature of hyperbolic agents is that they exhibit steeper discounting for time intervals closer to the present (...). As a result, intertemporal trade-offs shift with the mere passage of time, and plans or projects that seemed optimal yesterday need no longer be optimal today [37] (p. 1).

Discounting of the future has long since been a central topic in economics [13], and in a broader sense, discrepancies between human judgement and actions concerning the future have always been discussed (this is known as "akrasia"; see, for instance, Reference [38], pp. 4-11).

\subsubsection{Decreasing Impatience}

As Delfmann et al. [39] have remarked, the "necessity to specifically model people as actors always arises when the people in question possess levels of freedom which they can utilize in their actions".

Time inconsistency is an instance of this type, as it has an agent exhibit incongruent behavior, with judgement and action not aligned, thus not only acknowledging levels of freedom utilized in actions, but done so in a manner that does not fit well with classic rationality assumptions:

"If we are to discuss the possibility of agents willingly or knowingly opting in favor of courses of action that they deem to be inferior, we have just treaded upon well-worn philosophical ground known as akrasia. The term akrasia means incontinence or lack of mastery" [38] (p. 4).

Formally, if we are looking at decisions over time, as over sequences of dated outcomes (denoted, for now, by $(x, t)$, for $x$ being realized with delay $t$ from now), we have an analogous property in the stationarity assumption (we use $\succ$ for strong preference and $\succeq$ for weak preference):

$$
(\mathrm{x}, \mathrm{t}) \succ(\mathrm{y}, \mathrm{s}) \wedge \mathrm{t}<\mathrm{s} \wedge \mathrm{x}<\mathrm{y} \Leftrightarrow(\mathrm{x}, \mathrm{t}+\varepsilon) \succ(\mathrm{y}, \mathrm{s}+\varepsilon)
$$

Preference $(\succ)$ between two prospects is preserved through mutual translation by the same delay $(\varepsilon)$. If this holds, constant ("exponential") discounting takes place, fulfilling both transitivity and stationarity [40]. Someone whose preferences suffice the requirements of a weak ordering and thus correspond to the stationarity property would evaluate all future prospects appropriately at all times.

Decreasing impatience describes time-inconsistent behavior and serves as a selection criterion for representations, as in the following two-stage decision problem (see Figure 1): for someone, the choice is given to either immediately (at time 0 ) go for an outcome $\mathrm{z}$ out of $\mathrm{x}<\mathrm{z}<\mathrm{y}$ with utilities $\mathrm{u}(\mathrm{x})<\mathrm{u}(\mathrm{z})<\mathrm{u}(\mathrm{y})$, or to wait until some fixed later time at which all three choices, each at a fixed point in time, become available. Even though $\mathrm{z}$ is inferior to $\mathrm{y}$, since it is both delayed further and less in value (as indicated by the height of the bars in Figure 1 below), there may very well exist utility combinations that would make an agent pick the dominated choice $\mathrm{z}$ at time 0 as a measure of 
commitment or self-restraint, anticipating that at the time $\mathrm{x}$ is immediately available, he might go for the instant reward that is $x$. In this setting, only the discounting behavior according to function $C$ (see below) is compatible with a choice of $z$, while all three are hyperbolic with different parameter values.

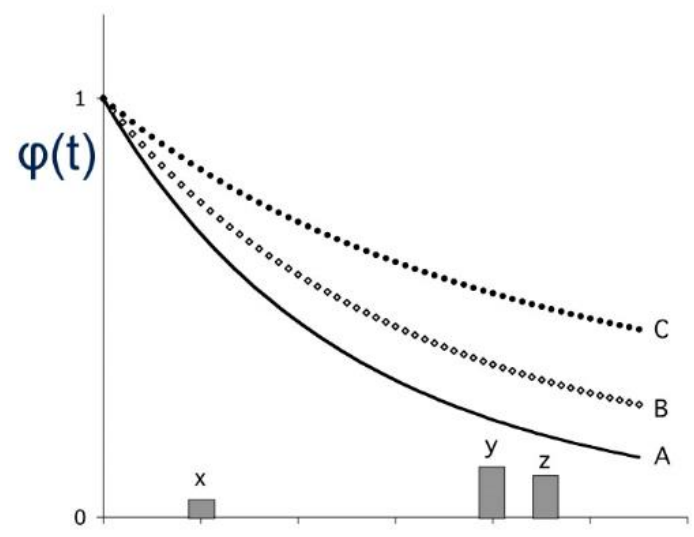

Figure 1. Representation of the two-stage decision problem [37] (p. 10).

The case is made for functions that tend most to result in the selection of dominated outcomes. Compared to $\mathrm{A}$ and $\mathrm{B}, \mathrm{C}$ allows for the most violations of dominance and thus can be seen as a stronger representation of dynamic inefficiency.

Assume someone has preferences represented by a utility function and strictly discounts future utility with $\varphi(t)$, where $\varphi(0)=1$, and $\lim \varphi_{(t \rightarrow \infty)}, \varphi(t)=0$. Generally, define decreasing impatience (DI) of $\succeq$ :

$$
(\mathrm{x}, \mathrm{t}) \sim(\mathrm{y}, \mathrm{s}) \Rightarrow(\mathrm{y}, \mathrm{s}+\varepsilon) \succeq(\mathrm{x}, \mathrm{t}+\varepsilon) \text { for } \varepsilon>0, \mathrm{y}>\mathrm{x}>0
$$

This poses a particular violation of stationarity in favor of the larger positive outcome, if evaluation takes place from a more distant point in time. Violations of stationarity can be compared: $\succeq$ exhibits more decreasing impatience [37] than $\succeq^{*}$ if for any intervals $0 \leq \mathrm{t}<\mathrm{s}, \sigma, \varepsilon$ and outcomes $0<\mathrm{x}^{\prime}<\mathrm{y}^{\prime}$, $(\mathrm{x}, \mathrm{t}) \sim(\mathrm{y}, \mathrm{s}) \wedge(\mathrm{x}, \mathrm{t}+\varepsilon) \sim(\mathrm{y}, \mathrm{s}+\sigma+\varepsilon) \wedge\left(\mathrm{x}^{\prime} \mathrm{t}^{\prime}\right) \sim^{*}\left(\mathrm{y}^{\prime}, \mathrm{s}^{\prime}\right) \Rightarrow\left(\mathrm{x}^{\prime}, \mathrm{t}+\varepsilon\right) \succeq *\left(\mathrm{y}^{\prime}, \mathrm{s}+\sigma+\varepsilon\right)$. More decreasing impatience holds if postponing the larger outcome does not resolve the preference reversal.

\subsubsection{Agent Types: Sophisticated and Naïve}

Two types of decision-makers are prevalent in the literature, sophisticated and naive [37] (p. 13): A sophisticated decision-maker foresees self-control issues and may pre-commit even to an inferior and delayed choice.

Sophistication: $\succeq$ allows for sophisticated two-stage violations of dominance at times $(\mathrm{t}, \mathrm{s}, \mathrm{r}, \tau)$ if $\succeq$ are DI and there exist outcomes $x, y$ with:

1. $\quad$ at $\mathrm{t}=0:(\mathrm{x}, \mathrm{t}+\tau)$ dominates $(\mathrm{x}, \mathrm{r}) \succeq(\mathrm{y}, \mathrm{s}+\tau)$

2. $\quad$ at $\mathrm{t}=\tau:(\mathrm{y}, \mathrm{s}) \succ(\mathrm{x}, \mathrm{t})(\Rightarrow \mathrm{u}(\mathrm{x})>\mathrm{u}(\mathrm{y}))$.

A naive agent decides without such foresight:

Naivety: $\succeq$ allows for naïve two-stage violations of dominance at times $(\mathrm{t}, \mathrm{s}, \mathrm{r}, \tau)$ if $\succeq$ are DI and there exist outcomes $x, y$ with:

1. at $\mathrm{t}=0:(\mathrm{y}, \mathrm{s}+\tau) \succeq(\mathrm{x}, \mathrm{r})$ dominates $(\mathrm{x}, \mathrm{t}+\tau)$

2. $\quad$ at $\mathrm{t}=\tau:(\mathrm{x}, \mathrm{t}) \succ(\mathrm{y}, \mathrm{s})(\Rightarrow \mathrm{u}(\mathrm{y})>\mathrm{u}(\mathrm{x}))$.

For either of the agents, "a time discount function leads to more dominated choices if and only if the $\log$ of the discount function is more convex. Let $\succeq$ be a preference order represented by $\mathrm{u}(\mathrm{x}), \mathrm{d}(\mathrm{t})$. Then the following conditions are equivalent:

(a) $\succeq$ exhibits DI,

(b) $\ln \mathrm{d}(\mathrm{t})$ is convex in $\mathrm{t} \geq 0$." [37] (p. 14). 


\subsubsection{Discount Functions and the Common Difference Effect}

Assume an agent whose decision at some point in time $(t=0)$ entails one realization of a sequence of outcome-time pairs, $\left(\mathrm{x}_{1}, \mathrm{t}_{1}\right),\left(\mathrm{x}_{2}, \mathrm{t}_{2}\right), \ldots,\left(\mathrm{x}_{\mathrm{n}}, \mathrm{t}_{\mathrm{n}}\right)$. These are evaluated via utility of the form $U=\sum_{i=1}^{n} u\left(x_{i}\right) d\left(0, t_{i}\right)$, where $\mathrm{d}(.,$.$) is called the "discount function" which in this case discounts$ utility from $t \geq 0$ to the present, $t=0$. Formally, we define a discount function as follows [41] (p. 5):

Discount function: Let $\Delta=\{(\mathrm{c}, \mathrm{t}) \in \mathrm{R} \times \mathrm{R}: 0 \leq \mathrm{c} \leq \mathrm{t}\}$. A discount function $\mathrm{d}: \Delta \rightarrow(0,1]$ satisfies the following:

1. for each $c \in[0, \infty), d(c, t)$ is a strictly decreasing (continuous) function of $t \in[c, \infty)$ into (onto) $(0,1]$ with $\mathrm{d}(\mathrm{c}, \mathrm{c})=1$.

2. for each $t \in[0, \infty), d(c, t)$ is a strictly increasing function of $c \in[0, t]$ into $(0,1]$.

With time consistency, we would have that $\mathrm{d}(\mathrm{s}, \mathrm{t})=\mathrm{d}(\mathrm{s}+\varepsilon, \mathrm{t}+\varepsilon)$ if $\varepsilon>0$ and $0 \leq \mathrm{s}<\mathrm{t}$ (stationarity of the discount factor; this is identical for equally long time-intervals). If instead we had an agent expressing a preference for two goods like $\left(\left(\mathrm{x}_{1}, \mathrm{~s}\right) \sim\left(\mathrm{x}_{2}, \mathrm{t}\right) \Leftrightarrow \mathrm{u}\left(\mathrm{x}_{1}\right) \mathrm{d}(0, \mathrm{~s})=\mathrm{u}\left(\mathrm{x}_{2}\right) \mathrm{d}(0, \mathrm{t})\right.$, and then brought forward in time both by $\mathrm{s}$, and if the agent would then express $\mathrm{u}\left(\mathrm{x}_{1}\right) \mathrm{d}(0,0)>\mathrm{u}\left(\mathrm{x}_{2}\right) \mathrm{d}(0, \mathrm{t}-\mathrm{s})$, we have what has been coined the "common difference effect", which "gives rise to dynamically inconsistent behavior, (...) [and] implies that discount rates should decrease as a function of the time delay over which they are estimated" [11] (p. 575). The discount functions for generalized hyperbolic discounting and quasi-hyperbolic discounting (special cases of the definition given above) can accommodate this phenomenon via decreasing impatience, as defined in Reference [41]:

$$
\mathrm{d}(\mathrm{c}, \mathrm{s}) \text { exhibits declining (decreasing) impatience if, for } \mathrm{t}>0 \text { and } \mathrm{c}<\mathrm{s}, \mathrm{d}(\mathrm{c}, \mathrm{s})<\mathrm{d}(\mathrm{c}+\mathrm{t}, \mathrm{s}+\mathrm{t})
$$

\subsection{Prae Ante}

While in an ex post view we have an assessment of returns to education and training measures as an investment, in ex ante, which are seen as distant and uncertain. With "ex ante," we are still employing hindsight since we can only call some decision present-biased well after it has taken place: By definition (1) a delay needs to have taken place, which, though not precisely defined, may be substantial for an evaluation that accounts for effects of foregone choices However, one may want to fill the parameters with meaning. Under the investment paradigm, we see that people decide against measures with substantial upfront or "contemplation" costs [40], the benefits of which led to take on the prae ante view, which motivates our survey. For the individual, the most influential factors identified in the literature can be subsumed under their socio-economic situation or -status, social and cultural capital, or family surroundings and expectations [42,43]. Higher earnings and socio-economic status are brought forward as key motivating factors and appear to have a high impact down the generations, even if one assumes that social status and economic situation can be secured and improved by higher education and degrees [44,45], attainment of such largely depends on the socio-economic status someone already has [46], and further on the socio-economic status of institutions attended [47].

As such, factors within the prae ante-period related to economic status are knowledge about education and training opportunities, expectation of (not) taking such opportunities, attitude towards rejection, the point in time when further education and training are first discussed, and whether someone is among the first within their surroundings to attend a given measure [48,49]. Those forming such a "transition group" show a comparative lack in information on administrative processes, financial support, and the possible choices. Cultural conflicts and isolation are both experienced [48]. Other factors stemming from experiences during the later stages of compulsory education include expectations about mobility and financial requirements, which, taken together with deficits in financial literacy, can cause some to decide against further education and training. In this context, higher socio-economic status is reported to counteract other perceived "harmful influences" such as low GPA or single parent-families [43]. 
Social and cultural capital, taken as the (perceived) capability to influence surroundings in general and people in particular, is the second decisive factor. Individuals with low social and cultural capital have to fight an uphill battle; they face taking part in additional education as confronting hierarchies, having to imitate or internalize behaviors prevalent in higher social classes, and risk their self-esteem and self-worth in the process [43].

Considering the prae ante view, this socio-cultural dimension is especially fitting, as those transitional hindrances are created at, or are prevalent from, an early age. During early years in high school, socio-cultural, socio-economic, psychosocial, gender-related, linguistic, and structural influences already separate people into groups with quite different outlooks on further education opportunities. As early as in grade ten, some begin to form expectations about continuing education and training after school, and by doing so, set goals and foster their own, intrinsic motivation, while others do not and consequently fall behind in that regard; these hard-to-recover deficits are firmly established at that time.

Further, directly related to economic status, we have that "social capital" in the form of communication and networks is a generally encouraging factor, as is the cultural perception linked to monetary status: the more elevated the latter, the more a "limitation mindset" gives way to something like an "abundance mentality," meaning that financial conditions or constraints are not so much experienced as limitations, but contextualized as opportunities [44]. Both taken together play a major part in what is known as "habitus," the "internalized expectations, views, tenets and attitudes" [43] (p. 26), all of that is foremost attained within a family and thus hardly subject to the influence of education institutions. Often, people do not even recognize this factor. Taking the picture of the "cards someone is dealt" (capital), "habitus" determines if/how they "play them," thus if they are able to activate their social/cultural capital [43]. This makes plain one further aspect: one of the first and most decisive factors lies within simply recognizing this mechanism.

Awareness of "habitus" appears to be one major precondition, which we attempt to elicit from our survey. Additional family-related factors include encouragement, aid with planning from an early stage, and again, financial support [43]. Within schools, the amount of guidance and curricula in general (quality and intensity of content) factor in. Worthy [50] relates unstable financial behavior to an age range between 18 and 30 years. One can find and employ ideas such as nudging [51], which, in the education and training context, attempt to mitigate inefficiencies (symptoms) caused by individual present bias.

\section{Materials and Methods}

\subsection{Empirical Study Design}

In Delfmann et al. [39] (p. 57), members of a working group of the Scientific Advisory Board of the German Logistics Association (BVL) lay down five key points "as the cornerstones of an understanding of logistics as an academic discipline". In their work, three ideal types of human beings in logistics contexts are differentiated: technical consideration of the human being, human beings as actors with limited rationality, and human beings exhibiting behavioral characteristics beyond the model of homo economicus. Our current work is concerned with the individual decision regarding education and training measures. Though this categorically excludes aspects from the first category (technical), we find our work as considering both limited rationality as well as relying on findings from behavioral science. As Reference [39] (p. 60) states:

logistical inquiry is unique in its aspiration to overcome the boundaries of established application-oriented scientific disciplines such as business administration, economics, engineering, informatics, the social sciences, etc. (... ). Logistics is rooted in these disciplines, but aims to advance knowledge through the synergistic combination of the knowledge bases of these root disciplines. 
In part, we follow remarks made in works, such as Mangan et al. [22] and Naslund [52], that advocate the benefits of utilizing both quantitative and qualitative methodologies while taking a cautious position with respect to mistaking narrow approaches with rigor. Our approach combines three of the four types of triangulation mentioned in Reference [22], data-, methodological-, and theory-triangulation.

As Bechara and Van de Ven [53] point out, "the dimensionality of the methods used should match the dimensionality of the phenomena observed" (p. 350), to avoid myopia and insufficient validity in the representation of these. "Triangulation increases the richness (and complexity) of problem representations, which decreases the likelihood of myopic representations that other stakeholders may perceive as being biased and misdiagnosed" (p. 350).

The current paper is meant to represent the theory and results that make up phase 1 (of 3) of the three-phase triangulated research methodology according to Reference [22]. Following the structure of this approach, our research as a whole regarding the prae ante view will be structured as follows.

Phase 1 is inductive and consists of exploratory interviews, a corresponding literature review, and a review of the modeling approaches to which the prae ante view is related. The deductive phase 2 will be mostly theoretical modelling, while phase 3, again, relies on quantitative survey data. Thus, phases 2 and 3 run in parallel. With reference to both method choice and the specifically logistics sector, from which we selected our subjects, the use of qualitative methods and their integration into multi-method research designs have been discussed in References [21,22], for example. For a broad perspective on qualitative methods, Reference [54] provides a succinct chronology of the development of their use. The seminal contribution was Glaser and Strauss [55], regarded as the defining work on grounded theory. References $[56,57]$ go as far as arguing that the intent for providing a guiding book on qualitative research at the time was for the larger part political as to put forth a codification of qualitative methods in what is known as the text on "The Discovery of Grounded Theory". The historical context is more thoroughly laid out in Reference [54]. The extensive interviews we conducted to gain our factors can be described as qualitative interviews in the sense of Witzel [58], as well as expert interviews in the sense of Meuser and Nagel [59]. The interviews had a decisively narrative character as in logistics functions ("white collar"). Regarding each decision from pre-school, the subjects were asked open questions with respect to clearly defined intervals of time. With respect to each interval, open questions regarding influencing factors on the career choice taking place in it were asked, without further restrictions on details, duration, etc. Only as soon as the interviewed themselves deemed their answers exhaustive and finished, we posed more detailed, pre-outlined questions, and only so if these had not been touched by the subjects before. We conducted these extensive open interviews with six professionals currently employed in logistics professions, where we asked what factors they found to be influential with respect to the respective subsequent step each of them had taken.

We use our definition of the prae ante view as before, meaning with respect to our subjects the time leading up to the decision to take up the occupation currently held, as well as for each career decision that happened before, where we define career decision as the decision for a transition between educational institutions, subjects of study, undergraduate-to-graduate, or vocational training. Up to entering the job market, we usually found four to six of these transitions and corresponding decisions, depending on individual career paths and perception of what constitutes a transition that required a specific decision. Each time, we asked the same simple question for factors influencing the next decision ahead. Summarizing, grouping and coding of the paraphrased answers gave our prae ante-factors as explained below. Extended narrative answers and our inductive approach allowed for variations in the degree of abstraction necessary for an expression to constitute such a factor. We chose a two-fold approach: (i) based on the factors we identified in the literature review, we examined which descriptions (by the subjects) could be aligned with those definitions, that is with the findings and descriptions in a scientific language, and (ii) further prevalent factors we subsumed under our terminology as given below. 
Although our questionnaires, given the number of participants, allowed for a distinction of up to 36 decisions regarding transitions as described above, we refrained from counting and ordering similar descriptions by frequency of being mentioned. Rather, we proceeded with the distinctions of factors every subject mentioned, and given so, refinements of these. Further, factors identified in the literature review that no one referred to in practice are also elaborated upon (e.g. lack of awareness of the role social and cultural capital). Then, pairs of factors out of which exactly one has been mentioned by a subject, and factors that remained important over time, thus referred to throughout an interview, though labelled slightly different. For instance, this can be one particular sort of influence subjects ascribed to different people at different points in time. Having categorized the influential factors described by the subjects as outlined above, only a few remain uncategorized, which we will discuss separately.

\subsection{Evaluation}

From the literature review, we identified these factors: social capital, cultural capital; habitus and awareness of habitus; costs, especially upfront costs; long term perspective and orientation; external expectations; family surroundings; knowledge about education and training opportunities, expectation of taking such, expectation of being able to take such; belonging to a transition group, that is, being the first within one's surroundings to take a certain education and training measure; attitude towards success and rejection; finances, mobility (leftmost column in Figure 2).

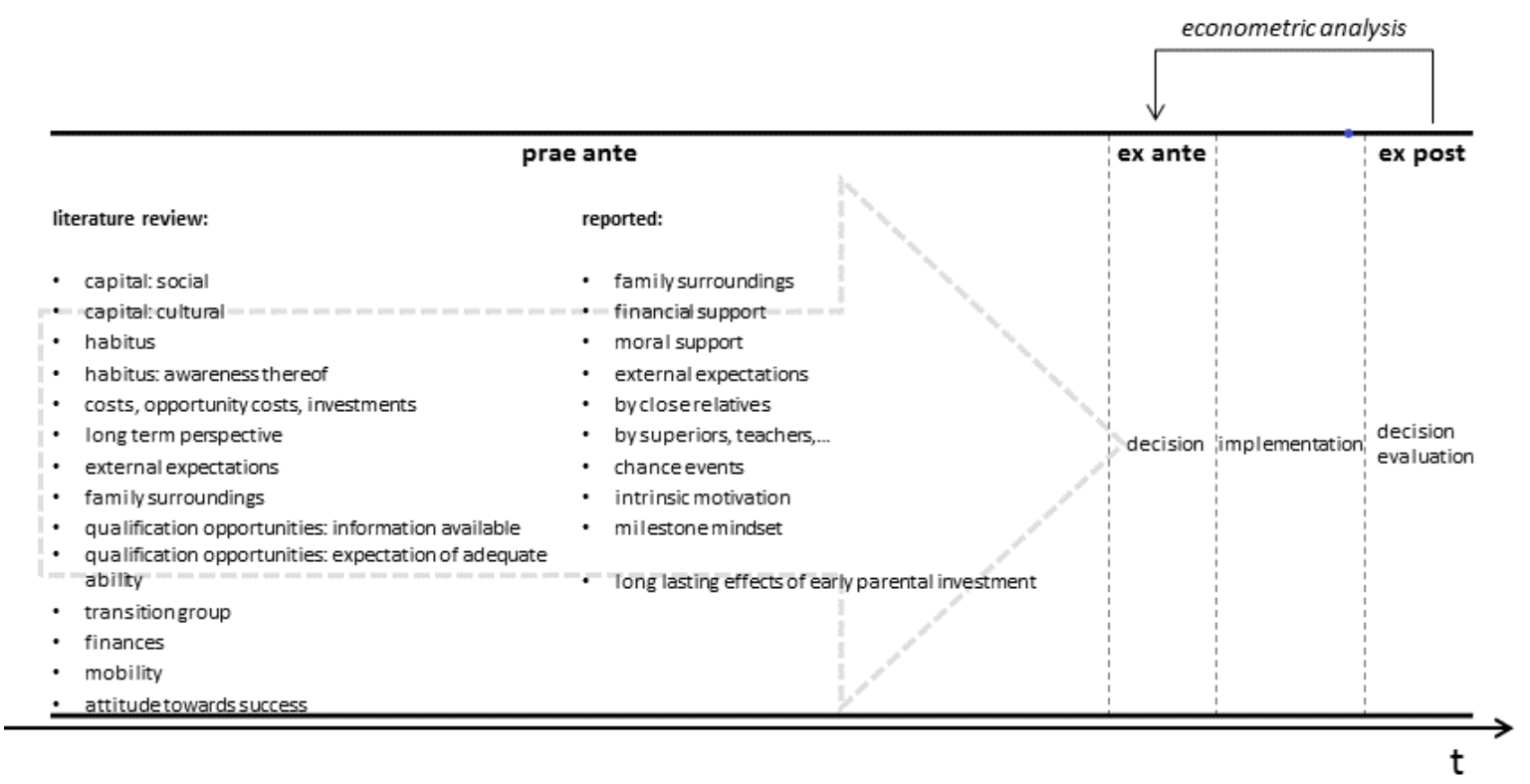

Figure 2. Factors informing the prae ante view.

One of the subjects expressed awareness of habitus, though not mentioning the term explicitly. Two elaborated on their initial and persisting awareness of substantial upfront (opportunity) costs regarding the acquisition of academic degrees. Two subjects mentioned a long-term orientation that had been present since their early high school years. With one exception, every subject stressed the decisive role of family surroundings in extenso, which should not come as a surprise given, for instance, recent findings by Castro et al. [60]. For all early age decisions (up to high school), subjects included supportive parents in their definition of family surroundings. Concerning later stages, this definition broadened to include finances and mobility, as well as being given job or internship opportunities by close relatives. All but one subject talked about having had knowledge about education and training opportunities throughout their career, either obtained through parents, teachers, or peers. For none of the decisions (not subjects) examined, subjects stated they had taken it all by themselves. However, stating the motive of proving ability to themselves played a major part for many at later stages, that is, 
after high school. Here, subjects reported having kept career moves or enrollment in study programs secret from relatives or superiors until substantial progress had been made.

The most important factors described by subjects were family surroundings, as defined above, both with respect to financial and moral support, as well as the presentation with specific opportunities. The subjects at hand all came up with the influence of external expectations voiced by parents and close relatives, but at no point in any interview did they describe those as definite goals; subjects only ascribed these the character of guidelines. However, if these had been voiced, subjects reported to have followed through. Subjects ubiquitously reported this sort of guidance being given to them even after high school and after obtaining a first degree; however, the higher the degree, the more the role of advisor was reported to have shifted towards superiors, university teachers, or professors. This might suggest an extension of the work in Reference [60] to a time period after secondary school, where the parental investment is replaced with a more general definition of "supervisor" or "mentor". Though their influence at the career step in question was described as decisive by all subjects interviewed, all subjects also stressed that in their perception, chance events played a decisive part regarding the question who exactly assumed this role.

The second universally expressed factor was intrinsic motivation and linked to this is a factor we have named "milestone mindset," something all but one subject referred to with respect to all education and training decisions happening after high school. In this strongly preselected sample of successful careers in logistics with academic background, every subject assessed their decisions in hindsight as based on rather broadly formulated goals (as "working in an office environment" or "working in controlling" at its most precise) in combination with a perception of the process of their achievement as milestones and short-term sub-goals spanning no more than 3-6 months at most. With respect to all stages after high school, subjects expressed that this defining mindset of setting short-term goals provided them with resilience against failure. Regarding decisions at stages after high school, one of the subjects came up with the subject of delayed gratification as a decisive factor for their success. Another interpretation is that of adaptability alongside growing expertise as an influence for selection into more advanced careers or expert roles [61].

The next-most important factor reported by the subjects is closely linked to family surroundings, as it is either parental investment starting at an early age (subjects linked efforts from the pre-school period to present day-outcomes) or the strong desire to clearly differentiate themselves from their parents. No subject took a neutral position on this.

On the negative side, with respect to the factors identified in the theoretical literature, at none of the decision points was there any mention of monetary goals or recognizable awareness of the role social and cultural capital might have had in the individuals' careers. One subject even explicitly talked about absence of financial desires as a decisive factor for their motivation.

For completeness, the following list sums up the factors given by the subjects interviewed (Figure 2, second column from left), beginning with those deemed most decisive: family surroundings, with respect to financial and moral support as well as the presentation with specific opportunities. The following were ascribed the character of guidelines: external expectations voiced by parents and close relatives; at later stages superiors, university teachers, or professors, though not assessing these as requirements, subjects followed through with them. Chance events played a decisive role regarding the question of who exactly assumed an advisory and effectively co-decision rule, further intrinsic motivation and a "milestone mindset," and early age parental investment and its long term positive effects were stressed. There was no mention of monetary goals, social or cultural capital, or habitus. None of the subjects talked about these factors deemed decisive in literature [42,43], which possibly means subjects were unaware of these factors or chose not to talk about them. This can be examined further in a closed question large sample survey. This section may be divided by subheadings. It should provide a concise and precise description of the experimental results, their interpretation, and the experimental conclusions that can be drawn. 


\section{Discussion and Theory Development: A Model for Educational Choice}

Taking a further step from the survey results vis-à-vis evidence from the literature, one way is to examine the difference between these two collections of factors behind myopic decision-making in educational choice. The factors social and cultural capital, as well as habitus and awareness, were mentioned by the subjects interviewed insofar as the topics of family surroundings and financial and moral support have been addressed. However, interview subjects did not voice reflections regarding the extent to which these factors influenced their career paths, for instance, as in References [62-64]. Further, information about education and training opportunities was classified as crucial in the literature, however not so by those interviewed; subjects ascribed a decisive influence to chance events while this factor is neglected in the education literature.

Hyperbolic discounting with respect to educational choice is likely to happen if awareness of the actually influential factors listed above does not exist. Nonetheless, this does not exclude hyperbolic behavior even if awareness of these factors exists, as has been described by the type distinction (sophisticated vs. naive).

This choice behavior (myopia) might be seen as problematic if it incurs substantial cost, for instance, either if someone quits an education or training measure, or if someone does not qualify as much as his capabilities would allow. We claim that if someone would take into account the factors that have been mentioned by our subjects, as well as material considerations influencing the decision ex ante, there is potential to reduce the inefficiencies of "overqualifying," as it is represented by non-completion, as well as "underqualifying" of those individuals unaware of their additional potential for successful education. The educational choice situation is illustrated in Figure 3, which depicts education and training paths over time in the dimensions of earnings, formal qualification, and competence. These paths (capital letters) mark possible effects of education and training measures for individuals. The exact behavior after $t_{1}$ of competence growth is supposedly complex [65].

Here we are taking a view on education and training decisions from the perspectives of earnings (e), formal qualification (q), and competence levels (c) over time, where time refers to some time span during the career of an individual, during which an education and training decision happens. In the stylized example shown in Figure 3, we have three instances during some individual's career, indicated as $t_{1}<t_{2}<t_{3}$. At $t_{1}$, a decision about an education and training measure is taken. In Figure 3 we have depicted individual education and training paths (marked A, B, C, and D). An ex ante view temporally corresponds to $t_{1}$, ex post corresponds to any $t>t_{3}$. We assume the earnings function during a measure to be constant at best (as in cases A and B), or declining, for instance in the case of student loans ( $\mathrm{C}$ and D). At $t>t_{3}$ a discrete jump in earnings signifies possible, better employment opportunities taken by the individual (A and B), lagged for reasons of job market frictions. This is assumed part of the individual's expectations ex ante.

For prae ante, this has not been reported by the subjects interviewed, for any education or training decision. With $t_{2}$, we mark a point in time during some measure when it was aborted before completion (as for path C). For this case, an individual would take into account possible sunk costs, lower earnings (since time has passed and requirements have not declined per assumption, while formal qualification remained on the same level as before), and delay until a change in earnings takes place. These would all be part of the considerations a rational decision-maker would take ex ante (in $\mathrm{t}_{1}$ ), while with regard to the prae ante period, no subject expressed considerations of this kind (Figure 2). We modeled formal qualification (q) as a step function, since individuals cannot expect their education and training to be recognized without formal credentials (which are assumed to exist after completion in $\mathrm{t}_{3}$ for individual paths $\mathrm{A}$ and $\mathrm{B})$. 


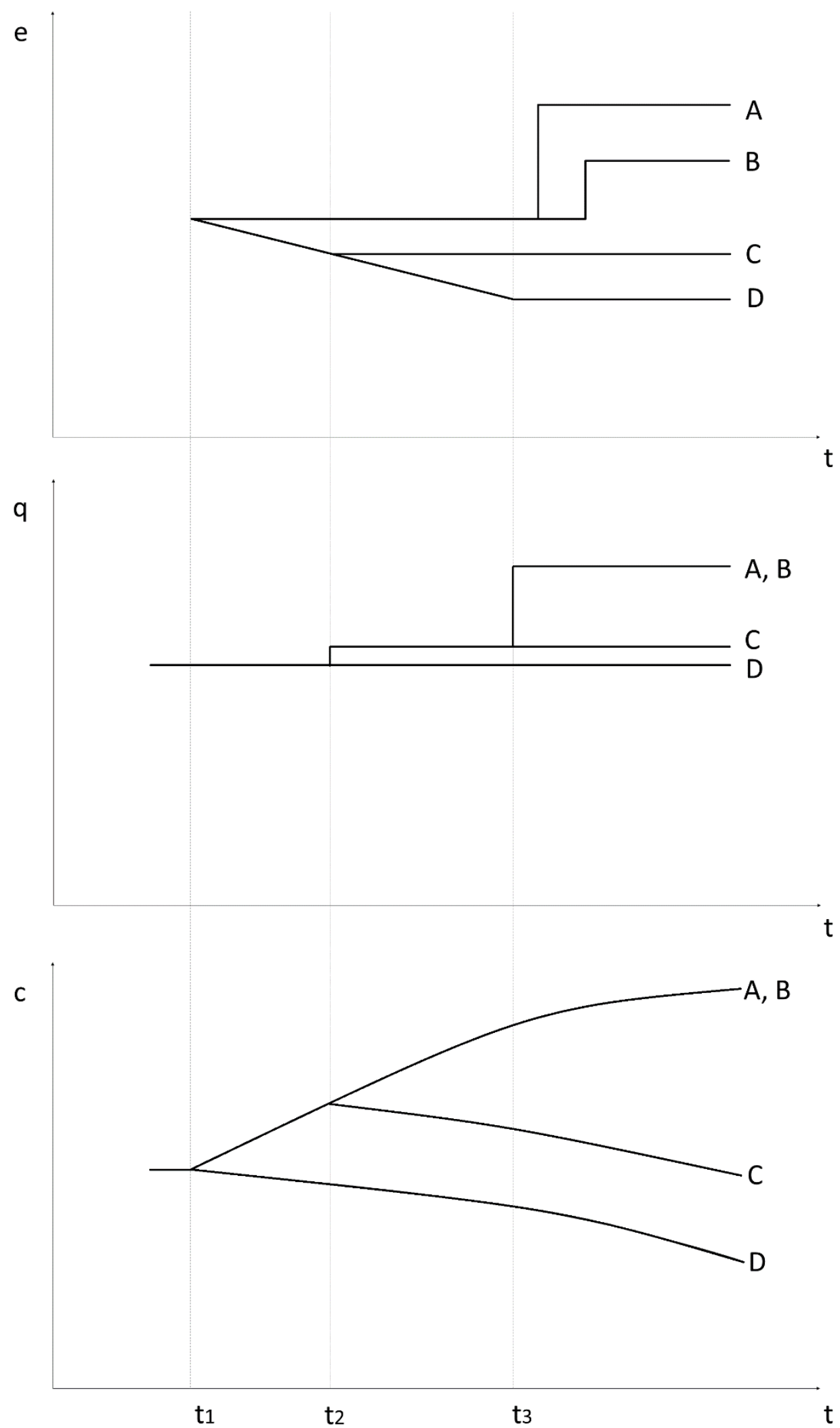

Figure 3. Education and training paths over time in the dimensions earnings (e), formal qualification $(\mathbf{q})$, and competence (c) over some timespan during the career of an individual, during which an education and training decision happens. Three instances during some individual's career, indicated as $t_{1}<t_{2}<t_{3}$. Four exemplary individual education and training paths are marked as A, B, C, and D. 
Competence, in contrast, is accumulated over the entire process of education and training and possibly beyond, though an individual has to assume uncertainty about this over a growing time horizon. Thus, the only definitive assumption we make here is that competence has the property of being strictly declining over time and can be enhanced to a higher level by (ongoing) education and training measures, after which it declines again. Concerning prae ante, we claim that the crucial point is that, if someone aborts an education and training measure at $t_{2}$ (as for path $C$ ), this might happen for a number of contingent reasons. However, we claim that a substantial proportion of the behavior as shown by path $\mathrm{C}$ occurs because of omission of the prae ante factors awareness of habitus, and social and cultural capital, not because of their presence or absence, but because of the individual being unaware of their influence and of the size of this influence. The same reasoning may hold for $D$, who might be unaware of her potential for higher qualification.

\section{Conclusions}

Two clusters of factors behind myopic decision making in educational choice by logistics personnel have been compiled in this paper from surveying the literature and by semi-structured expert interviews. To summarize, these collections do not overlap with regard to a few topics crucial to individual career choice and its addressing by institutions, as well as logistics and HRM practitioners. Interview participants did not apparently reflect on the extent to which the factors of social and cultural capital and habitus impact career paths [62-64]. Awareness of information about education and training opportunities was not mentioned as important by the interviewed logistics managers. Rather, a decisive influence of chance events was stressed. This factor does not occur in the education literature explicitly. This might be explained by the nature of formal modeling approaches to ascribe these influences to residual noise. However, realizing and quantifying the extent to which career choice is in fact not calculable may inspire discussions for both researchers and practitioners.

While hyperbolic discounting and related myopia with respect to educational choice has been described and modeled with the type distinction (sophisticated vs naive), it can also be linked to lack of awareness of the actually influential factors as we found in our empirical results.

To practitioners, this choice behavior is relevant because it may account for substantial cost, for instance, either if someone quits an education or training measure, or if someone does not qualify as much as his capabilities would allow; further, it accounts for friction costs of onboarding measures. If HRM practitioners and logistics employees would take into account the factors that have been mentioned by interview participants, as well as material considerations influencing the decision ex ante, there is potential to reduce the inefficiencies and costs of "overqualifying," as it is represented by non-completion, as well as "underqualifying" of those individuals unaware of their additional potential for successful education.

Including our prae ante view outlined here, thus accessing the issue of myopia in educational choice with an ample view, can prevent inefficiencies caused by undereducation in the sense of lost potential, as well as overchallenging as a result of too ambitious choices, which may result in non-completion (e.g., of a degree). This contribution has shown new insights in order to foster the discussion in intertemporal decision-making with a focus on the topics of education and careers, and a problem-centered approach to methodology. Further work will be concerned with the development of benchmarks for a more comprehensive assessment of education paths. A first step towards this end will be the examination of those factors found to be highly predictive of educational and career success in the literature while completely neglected by interview subjects asked openly about influential factors for their education and career decisions (Section 3.2), preferably using a closed-question, large-sample survey. The sample was pre-selected in that it consisted of individuals on a promising career path, had successfully acquired multiple vocational and academic degrees, and had expressed the presence of a character trait we dubbed a "milestone mindset" as highly important. All but one subject did not elaborate on the reasons behind possessing this trait, which was implicitly described by the subjects as a combination of the ability to delay gratification, intrinsic motivation, and further the ability 
to break down larger goals into short-term sub-goals. Concerning further research, we notice that examinations of the workings behind delayed gratification have been done extensively, for instance, by Duckworth, Tsukayama, and Kirby [66], Perez-Arce [67], Rybanska et al. [68], and Gabaix and Laibson [69]. Having gained qualitative insights with the current work, a consequential step will be to conduct a large-sample, quantitative survey and to provide a formal model including these factors and accounting for mid- to long-term talent planning [70].

Author Contributions: M.K. and T.N. conceived and designed the experiments; T.N. performed the experiments; M.K. and T.N. wrote the paper.

Acknowledgments: The presented research results are connected to the ERDF research project "MARTINA," project ID EFRE-0800013.

Conflicts of Interest: The authors declare no conflict of interest.

\section{References}

1. Guan, J.; Arthur, M.B.; Khapova, S.N.; Hall, R.J.; Lord, R.G. Career boundarylessness and career success: A review, integration and guide to future research. J. Vocat. Behav. 2018, in press. [CrossRef]

2. Bravo, J.; Seibert, S.E.; Kraimer, M.L.; Wayne, S.J; Liden, R.C. Measuring career orientations in the era of the boundaryless career. J. Career Assess. 2017, 253, 502-525. [CrossRef]

3. Latzke, M.; Kattenbach, R.; Schneidhofer, L.; Schramm, F.; Mayrhofer, W. Consequences of voluntary job changes in Germany: A multilevel analysis for 1985-2013. J. Vocat. Behav. 2016, 93, 139-149. [CrossRef]

4. Huo, B.; Han, Z.; Chen, H.; Zhao, X. The effect of high-involvement human resource management practices on supply chain integration. Int. J. Phys. Distrib. Logis. Manag. 2015, 458, 716-746. [CrossRef]

5. Mangan, J.; Gregory, O.; Lalwani, C. Education, Training and the Role of Logistics Managers in Ireland. Int. J. Logist. Res. Appl. 2001, 43, 313-327. [CrossRef]

6. Thai, V.V. Competency requirements for professionals in logistics and supply chain management. Int. J. Logist. Res. Appl. 2012, 152, 109-126. [CrossRef]

7. Lau, A.K.W. Teaching supply chain management using a modified beer game: An action learning approach. Int. J. Logist. Res. Appl. 2015, 181, 62-81. [CrossRef]

8. Dekker, R.; de Grip, A.; Heijke, $\mathrm{H}$. The effects of training and over-education on career mobility in a segmented labour market. Int. J. Manpower 2002, 23, 106-125. [CrossRef]

9. Klumpp, M.; Abidi, H.; Krol, B.; Stender, T.; Bioly, S. Berufswertigkeit und Logistikqualifikation; Logos: Berlin, Germany, 2013.

10. Suzuki, Y. Truck driver turnover: What rate is good enough? Int. J. Phys. Distrib. Logist. Manag. 2007, 378, 612-630. [CrossRef]

11. Loewenstein, G.; Prelec, D. Anomalies in intertemporal choice: Evidence and an interpretation. Q. J. Econ. 1992, 107, 573-597. [CrossRef]

12. Laibson, D. Golden eggs and hyperbolic discounting. Q. J. Econ. 1997, 1122, 443-478. [CrossRef]

13. Frederick, S.; Loewenstein, G.; O'Donoghue, T. Time discounting and time preference: A critical review. J. Econ. Lit. 2002, 402, 351-402. [CrossRef]

14. Andersen, S.; Harrison, G.W.; Lau, M.I.; Rutström, E.E. Discounting behavior: A reconsideration. Eur. Econ. Rev. 2014, 71, 15-33. [CrossRef]

15. Hasanefendic, S.; Heitor, M.; Horta, H. Training students for new jobs: The role of technical and vocational higher education and implications for science policy in Portugal. Technol. Forecast. Soc. Chang. 2016, 113, 328-340. [CrossRef]

16. McDonald, C.C.; Goodwin, A.H.; Pradhan, A.K.; Romoser, M.R.; Williams, A.F. A review of hazard anticipation training programs for young drivers. J. Adolesc. Health 2015, 57, 15-32. [CrossRef] [PubMed]

17. Gollier, C.; Weitzmann, M.L. How should the distant future be discounted when discount rates are uncertain? Econ. Lett. 2010, 1073, 350-353. [CrossRef]

18. Wakker, P.P. Prospect Theory for Risk and Ambiguity; Cambridge University Press: Cambridge, UK, 2010.

19. Olea, J.L.M.; Strzalecki, T. Axiomatization and Measurement of Quasi-Hyperbolic Discounting. Q. J. Econ. 2014, 1293, 1449-1499. [CrossRef] 
20. Biewen, M.; Tapalaga, M. Life-cycle educational choices in a system with early tracking and 'second chance' options. Econ. Educ. Rev. 2017, 56, 80-94. [CrossRef]

21. Golicic, S.L.; Davis, D.F. Implementing mixed methods research in supply chain management. Int. J. Phys. Distrib. Logist. Manag. 2012, 428, 1-27. [CrossRef]

22. Mangan, J.; Lalwani, C.; Gardner, B. Combining quantitative and qualitative methodologies in logistics research. Int. J. Phys. Distrib. Logist. Manag. 2004, 347, 565-578. [CrossRef]

23. Easterby-Smith, M.; Thorpe, R.; Jackson, P.R. Management Research: An Introduction; Sage Publications: New York, NY, USA, 1991.

24. Ticehurst, G.W.; Veal, A.J. Business Research Methods; Longman: London, UK, 2000.

25. Sweeney, E. The people dimension in logistics and supply chain management-Its role and importance. In Supply Chain Management: Perspective, Issues and Cases; Thomas, A., Passaro, R., Eds.; McGraw-Hill: New York, NY, USA, 2013; pp. 73-82.

26. Ellinger, A.E.; Ellinger, A.D. Leveraging human resource development expertise to improve supply chain managers' skills and competencies. Eur. J. Trai. Dev. 2014, 38, 118-135. [CrossRef]

27. Tokar, T. Behavioural research in logistics and supply chain management. Int. J. Logist. Manag. 2010, 211, 89-103. [CrossRef]

28. Gammelgaard, B.; Larson, P.D. Logistics Skills and Competencies for Supply Chain Management. J. Bus. Logist. 2001, 222, 27-50. [CrossRef]

29. Wu, Y.J.; Huang, K.S.; Goh, M.; Hsieh, Y. Global logistics management curriculum: Perspective from practitioners in Taiwan. Supply Chain Manag. Int. J. 2013, 184, 376-388.

30. Murphy, P.R.; Poist, R.F. Skill requirements of senior-level logisticians. Int. J. Phys. Distrib. Logist. Manag. 1991, 213, 3-14. [CrossRef]

31. Keller, S.B.; Ozment, J. Research on personnel issues published in leading logistics journals: What we know and don't know. Int. J. Logist. Manag. 2009, 203, 378-407. [CrossRef]

32. Murphy, P.; Poist, R.F. Skill requirements of senior-level logisticians: A longitudinal assessment. Supply Chain Manag. Int. J. 2007, 126, 423-431. [CrossRef]

33. Lorentz, H.; Töyli, J.; Solakivi, T.; Ojala, L. Priorities and determinants for supply chain management skills development in manufacturing firms. Supply Chain Manag. Int. J. 2013, 184, 358-375. [CrossRef]

34. Hohenstein, N.O.; Feisel, E.; Hartmann, E. Human resource management issues in supply chain management research. Int. J. Phys. Distrib. Logist. Manag. 2014, 446, 434-463. [CrossRef]

35. Mincer, J. Schooling, Earnings and Experience; Columbia University Press: New York, NY, USA, 1974.

36. Eichberger, J.; Harper, I.R.L. Financial Economics; Oxford University Press: Oxford, UK, 1997.

37. Prelec, D. Decreasing impatience: A criterion for non-stationary time preference and hyperbolic discounting. Scand. J. Econ. 2004, 1063, 511-532. [CrossRef]

38. Hanson, C.; Ainslie, G. Thinking about Addiction; Rodopi: Amsterdam, The Netherlands, 2009.

39. Delfmann, W.; Dangelmaier, W.; Günthner, G.; Klaus, P.; Overmeyer, L.; Rothengatter, W.; Weber, J.; Zentes, J. Towards a science of logistics: Cornerstones of a framework of understanding of logistics as an academic discipline. Logist. Res. 2010, 2, 57-63. [CrossRef]

40. Ok, E.A.; Masatlioglu, Y. A theory of (relative) discounting. J. Econ. Theory 2007, 1371, 214-245. [CrossRef]

41. Al-Nowaihi, A.; Dhami, S. A Theory of Reference Time; University of Leicester Publishing: Leicester, UK, 2013.

42. Cincinnato, S.; de Wever, B.; van Keer, H.; Valcke, M. The Influence of Social Background on Participation in Adult Education. Adult Educ. Q. 2016, 662, 143-168. [CrossRef]

43. Temple, S.L. Factors that Influence Students' Desires to Attend Higher Education. Ph.D. Thesis, Seton Hall University, Hongkong, China, 2009.

44. Louie, V. Who makes the transition to college? Why we should care? What we know, and what we need to do. Teach. Coll. Rec. 2007, 109, 2-3.

45. Carnevale, A.P.; Rose, S.J. Socioeconomic status, race/ethnicity, and selective college admissions. In America's Untapped Resource: Low-Income Students in Higher Education; Kahlenberg, R.D., Ed.; The Century Foundation: New York, NY, USA, 2004; pp. 101-156.

46. Adelman, C. The Toolbox Revisited: Paths to Degree Completion from High School through College; U.S. Department of Education: Washington, DC, USA, 2006.

47. Zwick, R.; Himelfarb, I. The Effect of High School Socioeconomic Status on the Predictive Validity of SAT Scores and High School Grade-Point Average. J. Educ. Meas. 2011, 482, 101-121. [CrossRef] 
48. Bloom, J. (Mis)reading social class in the journey towards college: Youth development in urban America. Teachers Coll. Rec. 2007, 109, 343-368.

49. Kahlenberg, R.D. America's Untapped Resource: Low-Income Students in Higher Education; The Century Foundation: New York, NY, USA, 2004.

50. Worthy, J. Only the names have been changed: Ability grouping revisited. Urban Rev. 2010, 42, $271-295$. [CrossRef]

51. Calzolari, G.; Nardotto, M. Nudging with Information: A Randomized Field Experiment; Centre for Economic Policy Research (CEPR) Publishing: London, UK, 2011.

52. Naslund, D. Logistics needs qualitative research-Especially action research. Int. J. Phys. Distrib. Logist. Manag. 2002, 325, 321-338. [CrossRef]

53. Bechara, J.; van de Ven, A.H. Triangulating philosophies of science to understand complex organizational and managerial problems. In Philosophy and Organization Theory (Research in the Sociology of Organizations, Volume 32); Tsoukas, H., Chia, R., Eds.; Emerald Group Publishing Ltd.: Bingley, UK, 2011; pp. 343-364.

54. Gobo, G. The renaissance of qualitative methods. Forum Qual. Soc. Res. 2005, 63, 42.

55. Glaser, B.G.; Strauss, A.L. The Discovery of Grounded Theory: Strategies for Qualitative Research; Aldine Publishing Company: Chicago, IL, USA, 1967.

56. Fielding, N. The resurgence, legitimation and institutionalization of qualitative methods. Forum Qual. Soc. Res. 2005, 62, 32.

57. Turner, B.A. Some practical aspects of qualitative data analysis: One way of organizing the cognitive process associated with the generation of grounded theory. Qual. Quant. 1981, 15, 225-247. [CrossRef]

58. Witzel, A. The problem-centered interview. Forum. Qual. Soc. Res. 2000, 11, 22.

59. Meuser, M.; Nagel, U. Das ExpertInneninterview-Wissenssoziologische Grundlagen und methodische Durchführung. In Handbuch Qualitative Forschungsmethoden in der Erziehungswissenschaft; Friebertshäuser, B., Prengel, A., Eds.; Beltz Juventa: Weinheim, Germany, 2002; pp. 481-491.

60. Castro, M.; Expósito-Casas, E.; López-Martín, E.; Lizasoain, L.; Navarro-Asencio, E.; Gaviria, J.L. Parental involvement on student academic achievement: A meta-analysis. Educ. Res. Rev. 2015, 14, 33-46. [CrossRef]

61. Bohle-Carbonell, K.; Stalmeijer, R.E.; Könings, K.D.; Segers, M.; van Merriënboer, J.J.G. How experts deal with novel situations: A review of adaptive expertise. Educ. Res. Rev. 2014, 12, 14-29. [CrossRef]

62. Hartmann, M.; Kopp, J. Elitenselektion durch Bildung oder durch Herkunft? Kolner. Z. Soziol. Sozialpsychol. 2001, 533, 436-466. [CrossRef]

63. Bourdieu, P. The forms of capital. In Handbook of Theory and Research for the Sociology of Education; Richardson, J.G., Ed.; Greenwood Press: New York, NY, USA, 1986; pp. 241-258.

64. Mayrhofer, W.; Iellatchitch, A.; Meyer, M.; Steyrer, J.; Schiffinger, M.; Strunk, H. Going beyond the individual. J. Manag. Dev. 2004, 239, 870-884. [CrossRef]

65. Schmidt, S.; Zlatkin-Troitschanskaia, O.; Fox, J.P. Pretest-Posttest-Posttest Multilevel IRT Modeling of Competence Growth of Students in Higher Education in Germany. J. Educ. Meas. 2016, 533, 332-351. [CrossRef]

66. Duckworth, A.L.; Tsukayama, E.; Kirby, T.A. Is it really self-control? Examining the predictive power of the delay of gratification task. Pers. Soc. Psychol. Bull. 2013, 397, 843-855. [CrossRef] [PubMed]

67. Perez-Arce, F. The effect of education on time preferences. Econ. Educ. Rev. 2017, 56, 52-64. [CrossRef]

68. Rybanska, V.; McKay, R.; Jong, J.; Whitehouse, H. Rituals Improve Children's Ability to Delay Gratification. Child Dev. 2017, 892, 349-359. [CrossRef] [PubMed]

69. Gabaix, X.; Laibson, D. Myopia and Discounting; National Bureau of Economic Research (NBER) Publishing: Cambridge, MA, USA, 2017.

70. Moheb-Alizadeh, H.; Handfield, R.B. Developing Talent from a Supply-Demand Perspective: An Optimization Model for Managers. Logistics. 2017, 1, 5. [CrossRef]

(C) 2018 by the authors. Licensee MDPI, Basel, Switzerland. This article is an open access article distributed under the terms and conditions of the Creative Commons Attribution (CC BY) license (http://creativecommons.org/licenses/by/4.0/). 